\title{
Catalytic dehydrogenation of formic acid over palladium nanoparticles immobilized on fibrous mesoporous silica KCC-1
}

\author{
Siqian Zhang, Yingjie Qian, Wha-Seung Ahn* \\ Department of Chemistry and Chemical Engineering, Inha University, Incheon 402-751, Republic of Korea
}

\section{A R T I C L E I N F O}

\section{Article history:}

Received 9 December 2018

Accepted 14 January 2019

Published 5 November 2019

\section{Keywords:}

Fibrous nanosilica

KCC-1

Palladium nanoparticles

Hydrogen storage

Formic acid dehydrogenation

\begin{abstract}
A B S T R A C T
Uniform Pd nanoparticles immobilized on $N$-(3-trimethoxysilylpropyl)diethylenetriamine (PDETA)-functionalized fibrous silica KCC-1 (Pd/KCC-1-PDETA) were prepared with a mean Pd particle size of $2.8 \mathrm{~nm}$. After characterization using powder X-ray diffraction, X-ray photoelectron spectroscopy, and $\mathrm{N}_{2}$ adsorption-desorption isotherms, Pd/KCC-1-PDETA was used as catalyst for additive-free dehydrogenation of formic acid to produce $\mathrm{H}_{2}$. Pd nanoparticle catalysts supported on two other mesoporous silica materials (MSF and KIT-6) were also synthesized to examine how the support affects the reaction. Among the three catalysts, Pd/KCC-1-PDETA exhibited significant catalytic activity (a turnover frequency of $332 \mathrm{~h}^{-1}$ at $323 \mathrm{~K}$ and $100 \%$ selectivity towards hydrogen), owing to the unique fibrous morphology of KCC-1 and the presence of amine groups that reduced the Pd particle size and improved the access of reactant to the catalytically active Pd sites. The influence of Pd loading (2-10 wt.\%), reaction temperature, and reaction time was also examined for the dehydrogenation reaction. Pd/KCC-1-PDETA was recovered easily after the reaction and showed good reusability up to five times without any significant loss in catalytic performance.
\end{abstract}

(C) 2019, Dalian Institute of Chemical Physics, Chinese Academy of Sciences. Published by Elsevier B.V. All rights reserved.

\section{Introduction}

Hydrogen is one of the most promising power sources for clean and sustainable energy supply, with the main advantages of easy conversion to electric or mechanical energy, high energy density (3 times higher than that of fossil fuels), and producing water as the only product after reaction with oxygen [1]. Currently, the main obstacles to commercial utilization of hydrogen as a power source are controllable storage and efficient release of hydrogen. In this regard, various chemical hydrogen storage materials including formic acid (FA), ammonia borane, and sodium borohydride were investigated to replace the classic pressurization or low-temperature liquefaction [2]. FA, among these, is a convenient and safe hydrogen carrier owing to its high hydrogen content, non-toxicity, outstanding stability, easy regeneration, and availability (produced as a major byproduct of the biomass conversion process). FA dehydrogenation reaction releases hydrogen and $\mathrm{CO}_{2}$ as a by-product (eqn. (1)) in the presence of a catalyst [3]. The dehydration reaction (eqn. (2)) can also occur to produce $\mathrm{CO}$ as an impurity, which is poisonous to the novel metal catalysts in hydrogen fuel cells [4].

$$
\begin{gathered}
\mathrm{HCOOH}(\mathrm{l}) \rightarrow \mathrm{CO}_{2}(\mathrm{~g})+\mathrm{H}_{2}(\mathrm{~g}), \Delta G_{298}=-48.8 \mathrm{~kJ} \mathrm{~mol}^{-1} \\
\mathrm{HCOOH}(\mathrm{l}) \rightarrow \mathrm{H}_{2} \mathrm{O}(\mathrm{l})+\mathrm{CO}(\mathrm{g}), \Delta G_{298}=-28.5 \mathrm{~kJ} \mathrm{~mol}^{-1}
\end{gathered}
$$

Even though several homogeneous catalysts were reported for FA dehydrogenation [3], heterogeneous catalysts are pre-

\footnotetext{
* Corresponding author. Tel: +82-328607466; Fax: +82-328720959; E-mail: whasahn@inha.ac.kr This work was supported by C1 Gas Refinery Program (2015M3D3A1A01064899) by the Ministry of Science, ICT \& Future Planning, and also by Basic Science Research Program through the National Research Foundation of Korea funded by the Ministry of Education (Grant No.: NRF-2015R1A4A1042434).

DOI: S1872-2067(19)63303-6 | http://www.sciencedirect.com/science/journal/18722067 | Chin. J. Catal., Vol. 40, No. 11, November 2019
} 
ferred due to their better reusability and recoverability for practical applications. Some of the heterogeneous catalysts demonstrated satisfactory catalytic activity and selectivity for $\mathrm{H}_{2}$, and various monometallic and multi-metallic nanoparticles such as Pd [5,6], Au [7], AgPd [8], PdNi@Ni [9], and CoAuPd [10] have been reported so far for FA dehydrogenation reaction at low temperatures sometimes even without using additives (such as sodium formate, triethylamine, and others). Song et al. [6] reported that finely-dispersed Pd nanoparticles deposited on amine-functionalized graphene oxide exhibited a good turnover frequency (TOF) of $3810 \mathrm{~h}^{-1}$ in a FA-sodium formate system at room temperature. Ojeda and Iglesia [7] prepared a $\mathrm{Au}$-deposited $\mathrm{Al}_{2} \mathrm{O}_{3}$ catalyst for dehydrogenation of $\mathrm{FA}$ at $350 \mathrm{~K}$, showing better catalytic activity than Pt-deposited $\mathrm{Al}_{2} \mathrm{O}_{3}$. Qin and co-workers [9] showed that the introduction of nickel could improve the catalytic activity of Pd nanoparticles in FA aqueous solution, and the resultant PdNi@Ni nanoparticles gave a high TOF of $577 \mathrm{~h}^{-1}$ in a mixture of FA and sodium formate at room temperature. Among the various metal nanoparticles, Pd-based nanoparticles have been mostly employed as catalyst for hydrogen release in FA dehydrogenation because of their high catalytic activity and stability.

In addition to the selection of active metal species, the design and/or selection of a support material also strongly affect the catalytic activity of Pd nanoparticles in FA dehydrogenation [11]. However, only limited cases of solid-supported palladium nanoparticle systems have been tested for FA dehydrogenation up to now. Lee and co-workers [12] used a mesoporous silica supported $\mathrm{Pd}-\mathrm{MnO}_{x}$ nanocatalyst system for $\mathrm{H}_{2}$ release from $\mathrm{FA}$ at room temperature, and reported excellent FA decomposition with a TOF of $540 \mathrm{~h}^{-1}$. More recently, Navlani-García and co-workers [13] used Pd deposited on zeolite (H-BETA) but observed a TOF value of only $64 \mathrm{~h}^{-1}$. It was envisaged that a support with an open pore structure would help to improve the catalytic performance of Pd catalysts by ensuring high accessibility of the supported Pd nanoparticles to the reactant molecules [14]. In this case, KCC-1, which possesses an open pore structure and easy accessibility owing to its unique fibrous morphology, was selected as a support for Pd nanoparticles [15]. KCC-1 can be synthesized in a reverse micelle template process in organic solvent [16]. Some papers have reported KCC-1 as an effective catalyst support material for the transfer hydrogenation of alkene [14], Suzuki coupling reaction [17], reduction of 4-nitrophenol [18], and dehydration of fructose [19] as well as working as an adsorbent for dyes [20] and $\mathrm{CO}_{2}$ capture [21].

In this work, Pd nanoparticles with different metal loadings on the $N$-(3-trimethoxysilylpropyl), diethylenetriamine (PDETA)-functionalized KCC-1 (Pd/KCC-1-PDETA) were prepared and tested for FA dehydrogenation reaction without additives at $323 \mathrm{~K}$. The catalytic performance of Pd/KCC-1-PDETA was compared with those Pd nanoparticles supported on mesoporous silica foam (MSF) [22] and KIT-6 [23], which have been widely applied as catalyst/support because of their promising textural properties in 3-D pore structures. The influence of reaction temperature and reaction time, and the catalyst recyclability was also examined. The resultant
2 wt.\% Pd/KCC-1-PDETA exhibited excellent catalytic activity with nearly $100 \%$ hydrogen selectivity towards FA dehydrogenation.

\section{Experimental}

\subsection{Chemicals}

Tetraethylorthosilicate (TEOS), cetyltrimethylammonium bromide, 1-butanol, P123 $\left(\mathrm{EO}_{20} \mathrm{PO}_{70} \mathrm{EO}_{20}, M_{v}=5800\right)$, acetic acid, ammonium fluoride, mesitylene, sodium silicate, $\mathrm{N}$-(3-trimethoxysilylpropyl)diethylenetriamine, sodium tetrachloropalladate(II) $\left(\mathrm{Na}_{2} \mathrm{PdCl}_{4}\right)$, sodium borohydride, formic acid, $\mathrm{HCl}$ solution (35 wt.\%), toluene, and ethanol were purchased from Sigma Aldrich. Urea was purchased from DUKSAN in Korea. All the chemicals were of reagent grade and used without further purification. Deionized water was used.

\subsection{Synthesis of KCC-1}

KCC-1 was prepared following the literature procedure [16] with minor modification. Firstly, TEOS ( $4.7 \mathrm{~mL}$ ) was added into a solution of 1-butanol $(2.2 \mathrm{~mL})$ and toluene $(51 \mathrm{~mL})$. A solution of cetyltrimethylammonium bromide $(1.7 \mathrm{~g})$ and urea (1.1 g) in water $(52 \mathrm{~mL})$ was then introduced. This mixture was vigorously stirred for $30 \mathrm{~min}$ at room temperature, followed by heating at $120{ }^{\circ} \mathrm{C}(393 \mathrm{~K})$ for $4 \mathrm{~h}$. The white product was collected by centrifugation, washed with water, and dried at $80^{\circ} \mathrm{C}$ ( $353 \mathrm{~K}$ ) for $12 \mathrm{~h}$. After that, the product was calcined at $560{ }^{\circ} \mathrm{C}$ (833 K) for $6 \mathrm{~h}$ to produce template-free KCC-1.

To study the effect of the support on FA dehydrogenation, MSF and KIT- 6 were synthesized according to the methods shown in the Supporting Information (SI).

\subsection{Amine functionalization of KCC-1, MSF, and KIT-6 silica supports}

Silica-PDETA was synthesized according to the procedure reported in the literature [24]. In a typical synthesis, KCC-1, MSF or KIT- 6 ( $0.5 \mathrm{~g}$ ) was dispersed in toluene ( $30 \mathrm{~mL}$ ) by sonication for $30 \mathrm{~min}$, and PDETA ( $1 \mathrm{mmol}$ ) was added under stirring at room temperature. After stirring the mixture at $80{ }^{\circ} \mathrm{C}$ ( $353 \mathrm{~K}$ ) for $24 \mathrm{~h}$, the product was recovered by centrifugation, washed with ethanol several times, and dried at $60{ }^{\circ} \mathrm{C}(333 \mathrm{~K})$ for $12 \mathrm{~h}$. The samples are referred to as KCC-1-PDETA, MSF-PDETA, and KIT-6-PDETA, respectively.

\subsection{Synthesis of Pd nanoparticles immobilized on amine-functionalized silica supports}

Pd/silica-PDETA was prepared according to the procedure reported in the literature [25]. In the typical synthesis, silica-PDETA $(0.5 \mathrm{~g})$ was dispersed in water $(50 \mathrm{~mL})$ by sonication for $5 \mathrm{~min}$ followed by stirring for $10 \mathrm{~min}$ at room temperature. $\mathrm{Na}_{2} \mathrm{PdCl}_{4}$ solution $(2 \mathrm{~mL}, 0.05 \mathrm{~mol} / \mathrm{L}$ in water) was introduced, and the mixture was sonicated for $30 \mathrm{~min}$ followed by stirring for $2 \mathrm{~h}$ at room temperature. Sodium borohydride solution (1 
$\mathrm{mL}, 1 \mathrm{~mol} / \mathrm{L}$ in water) was then introduced for reduction. After stirring the mixture for $2 \mathrm{~h}$, the prepared catalyst was recovered by centrifugation, washed with water and ethanol several times, and dried at $80{ }^{\circ} \mathrm{C}(353 \mathrm{~K})$ for $16 \mathrm{~h}$. These samples were designated as 2 wt.\% Pd/KCC-1-PDETA, 2 wt.\% Pd/MSF-PDETA, and 2 wt.\% Pd/KIT-6-PDETA, respectively.

By changing the amount of the added $\mathrm{Na}_{2} \mathrm{PdCl}_{4}$ solution, 5 wt.\% and $10 \mathrm{wt} . \%$ Pd/KCC-1-PDETA were also prepared following the same method.

\subsection{Characterization}

The obtained Pd catalysts were characterized by various instrumentation, and the experimental details are described in SI.

\subsection{Catalytic FA dehydrogenation}

Catalytic performance in FA dehydrogenation was evaluated in a $50 \mathrm{~mL}$ three-necked round flask with water jacket, using an experimental set up shown in Fig. S1. In a typical experiment, a predetermined amount of Pd catalyst (mole ratio of Pd/FA = $0.01)$ and water $(15 \mathrm{~mL})$ were added in the flask, which was connected to a pressure-equalization funnel (containing 5 mmol FA), a gas burette, and Ar gas line. Before starting the experiment, the reaction medium was vigorously stirred for 30 min to obtain thermal equilibrium under inert conditions. The reaction was initiated after injecting FA ( $5 \mathrm{mmol}$ ) into the flask under vigorous stirring. The reaction temperature was maintained at $323 \mathrm{~K}$ by using the water circulator, and the volume of gas produced was measured by water displacement in the gas burette.

\section{Results and discussion}

\subsection{Catalyst characterization}

The silica-PDETA supports were prepared via a post-synthetic functionalization method to immobilize the $\mathrm{Pd}$ nanoparticles. PDETA plays the role of a tethering ligand to bind the Pd nanoparticles with high dispersion and uniform particle size [26]. The Pd contents in Pd/KCC-1-PDETA,

Table 1

Physicochemical properties of the silica-supported Pd catalysts.

\begin{tabular}{|c|c|c|c|c|c|}
\hline \multirow[t]{2}{*}{ Catalyst } & \multirow{2}{*}{$\begin{array}{c}\mathrm{S}_{\mathrm{BET}} \\
\left(\mathrm{m}^{2} / \mathrm{g}\right)\end{array}$} & \multirow{2}{*}{$\begin{array}{c}\mathrm{N}^{\mathrm{a}} \\
\text { (wt.\%) }\end{array}$} & \multirow{2}{*}{$\begin{array}{l}\text { Pd loading b } \\
\text { (wt. } \%)\end{array}$} & \multicolumn{2}{|c|}{$\begin{array}{c}\text { Fraction of Pd } \\
\text { species c }(\%)\end{array}$} \\
\hline & & & & $\mathrm{Pd}^{2+}$ & $\mathrm{Pd}^{0}$ \\
\hline KCC-1 & 520 & - & - & - & - \\
\hline KCC-1-PDETA & 231 & 6.13 & - & - & - \\
\hline 2 wt. $\%$ Pd/KCC-1-PDETA & 168 & 6.13 & 1.93 & 30 & 70 \\
\hline 5 wt. $\%$ Pd/KCC-1-PDETA & 114 & 6.13 & 4.89 & 39 & 61 \\
\hline 10 wt.\% Pd/KCC-1-PDETA & 90 & 6.13 & 9.80 & 40 & 60 \\
\hline MSF & 550 & - & - & - & - \\
\hline MSF-PDETA & 290 & 5.04 & - & - & - \\
\hline 2 wt.\% Pd/MSF-PDETA & 236 & 5.04 & 1.75 & 40 & 60 \\
\hline KIT-6 & 714 & - & - & - & - \\
\hline KIT-6-PDETA & 300 & 4.15 & - & - & - \\
\hline 2 wt.\% Pd/KIT-6-PDETA & 248 & 4.15 & 1.56 & 35 & 65 \\
\hline
\end{tabular}

${ }^{a}$ Estimated by EA. ${ }^{\mathrm{b}}$ Estimated by ICP-OES. ${ }^{\mathrm{c}}$ Estimated by XPS.
Pd/MSF-PDETA, and Pd/KIT-6-PDETA catalysts were found to be 1.93 wt.\%, 1.75 wt.\%, and 1.56 wt.\%, respectively (Table 1) by ICP-OES. The actual Pd loading amounts on $\mathrm{Pd} /$ KCC-1-PDETA are close to the expected loadings based on the Pd precursors (2 wt.\%) used during the preparation. The Pd contents on MSF-PDETA and KIT-6-PDETA were somewhat lower than the expected values due to the lower $\mathrm{N}$ contents (low functionalized PDETA) on these supports as detected by EA (Table 1).

The crystalline structure of the as-prepared Pd catalysts on different silica supports was examined by powder XRD as shown in Figs. 1 and S1. The pristine silica materials showed a broad peak at $2 \theta=22^{\circ}$ corresponding to their amorphous nature (Figs. 1(a), S2(a-1), and S2 (b-1)). The materials after PDETA grafting and Pd deposition showed similar XRD patterns to that of the respective pristine silica supports. The PDETA-functionalized silica supports with 2 wt.\% loaded Pd did not show any extra peak in the region of $35^{\circ}-80^{\circ}$ due to high dispersion of Pd nanoparticles [27], but those loaded with 5 and 10 wt.\% Pd showed a characteristic $\operatorname{Pd}(111)$ peak at $39.1^{\circ}$ (Fig. 1(d-e)).

The morphology and particle size of the silica-supported Pd catalysts were characterized using FE-TEM. As shown in Fig. 2(a), the Pd nanoparticles in 2 wt.\% Pd/KCC-1-PDETA were well-dispersed on KCC-1 and no coagulated Pd nanoparticles were detected, proving a strong contact between the Pd nanoparticles and the silica support [28]. The fibrous morphology of KCC-1 was maintained without any structural degradation after amine functionalization and Pd loading. The Pd particle size distribution, derived from the image in Fig. 2(a), indicates that about $90 \%$ of Pd nanoparticles are in the size range of $2-4 \mathrm{~nm}$ and the mean diameter of the Pd nanoparticles is $\sim 2.8 \mathrm{~nm}$ (Fig. 2(b)). It is likely that the high nitrogen content on the KCC-1 support (Table 1) limits the mobility and the agglomeration of the Pd particles. Pd nanoparticles deposited in 5 wt.\% Pd/KCC-1-PDETA and 10 wt.\% Pd/KCC-1-PDETA had mean particle sizes of 5.6 and $8.0 \mathrm{~nm}$, respectively, and some aggregated Pd nanoparticles were observed (Fig. 2(c-f)). Fig. 2(g) and 2(i) are the FE-TEM images of the as-prepared 2 wt.\% Pd/MSF-PDETA and 2 wt.\% Pd/KIT-6-PDETA, which showed

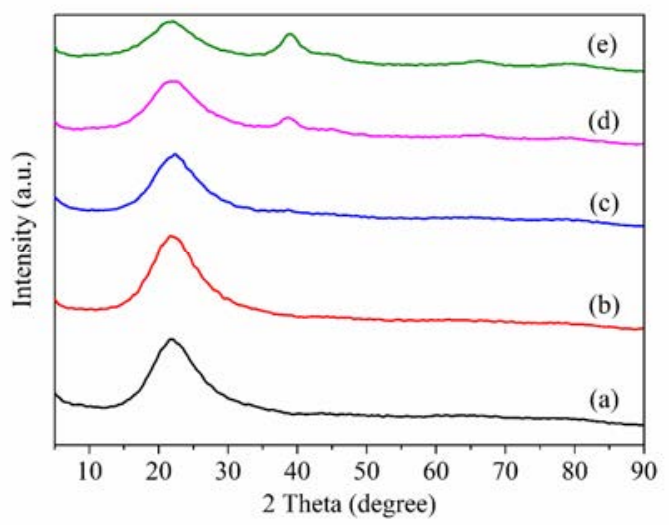

Fig. 1. Powder X-ray diffraction patterns for (a) KCC-1, (b) KCC-1-PDETA, (c) 2 wt.\% $\quad$ Pd/KCC-1-PDETA, (d) 5 wt.\% Pd/KCC-1-PDETA, and (e) 10 wt.\% Pd/KCC-1-PDETA. 

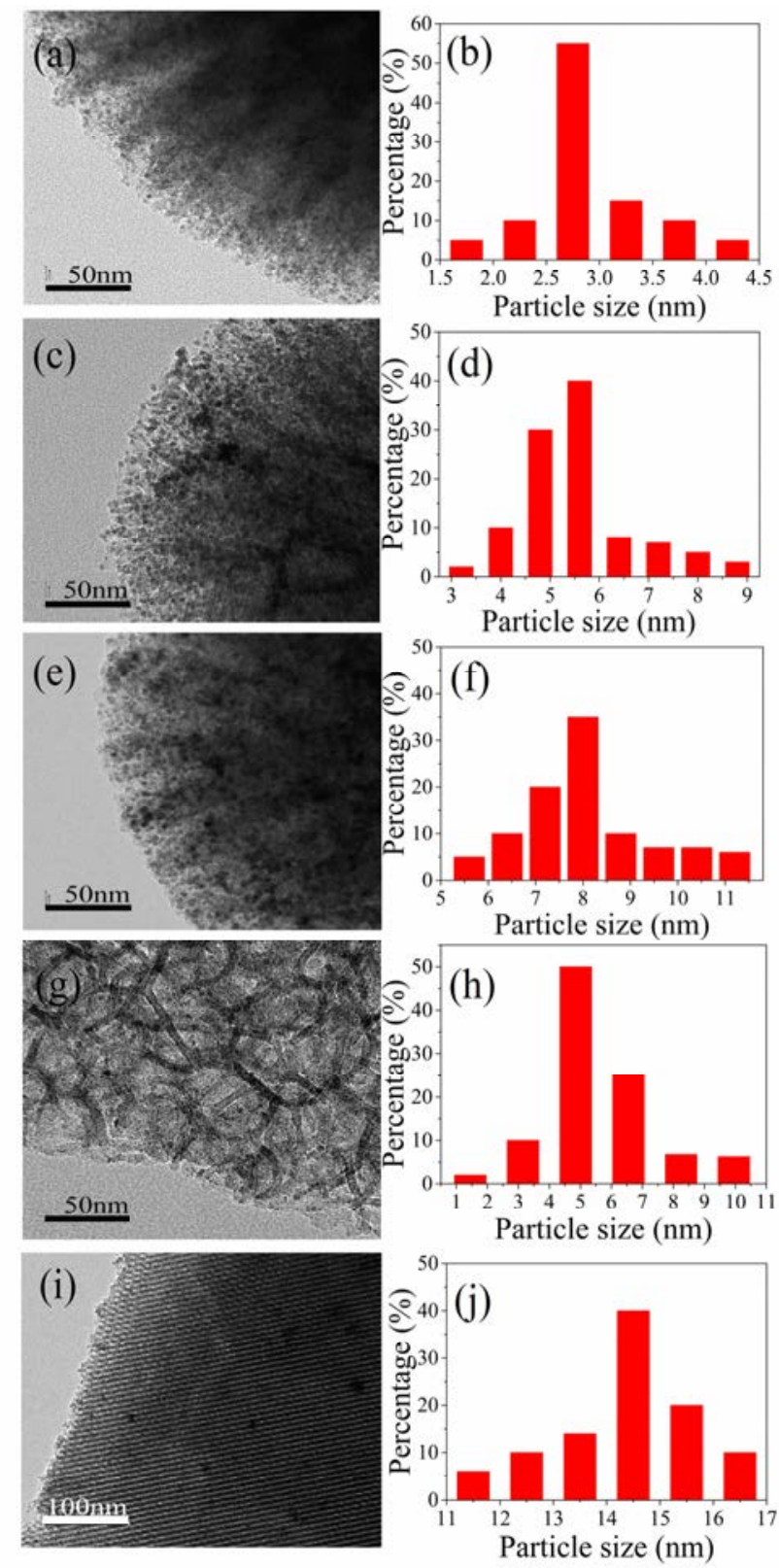

Fig. 2. FE-TEM images of the as-synthesized catalysts and the corresponding particle size distributions of Pd NPs. (a and b) 2 wt.\% Pd/KCC-1-PDETA; (c and d) 5 wt.\% Pd/KCC-1-PDETA; (e and f) 10 wt.\% Pd/KCC-1-PDETA; (g and h) 2 wt.\% Pd/MSF-PDETA; (i and j) 2 wt.\% Pd/KIT-6-PDETA.

that Pd nanoparticles were homogeneously dispersed on the respective support surfaces (MSF-PDETA and KIT-6-PDETA) with the mean particle size of 4.9 and $14.5 \mathrm{~nm}$ (Fig. 2(h) and 2(j)). These results clearly illustrated that the open morphology of KCC-1 has a beneficial effect in minimizing the Pd particle size due to highly accessible surface area [14]. HAADF-STEM with EDX analysis and the corresponding elemental mapping was done to examine the composition of 2 wt.\% Pd/KCC-1-PDETA. Closer inspection of the elemental mapping image for Pd in Fig. S3(e) showed that the Pd atoms were uniformly distributed over the entire KCC-1 support, which is con- sistent with the XRD and FE-TEM results.

To examine the textural properties of the as-prepared catalysts, $\mathrm{N}_{2}$ adsorption-desorption measurements were made at $77 \mathrm{~K}$. The obtained isotherms of KCC- 1 showed a combination of type I and IV isotherms with H1-type hysteresis (Fig. 3(a)). The surface area of PDETA-functionalized KCC-1 decreased from $520 \mathrm{~m}^{2} / \mathrm{g}(\mathrm{KCC}-1)$ to $231 \mathrm{~m}^{2} / \mathrm{g}$, confirming the successful grafting of amine species. After the immobilization of 2, 5, and 10 wt.\% Pd particles, the surface areas further decreased to 168,114 , and $90 \mathrm{~m}^{2} / \mathrm{g}$, respectively, accompanied by the disappearance of the pores around $2.2 \mathrm{~nm}$ in pristine KCC-1 (Fig. $3(\mathrm{~b})$ ). And these relatively small decreases in surface area could be attributed to the unique fibrous structure of KCC-1, in which the pores are not completely blocked by the introduced amines and Pd nanoparticles owing to the open structure [25]. The same tendency was also observed in other supports used in this study, and the surface areas of Pd/MSF-PDETA and $\mathrm{Pd} /$ KIT-6-PDETA also decreased from the respective pristine materials (see Fig. S4).

Fig. 4(a) shows the XPS spectra for 2 wt.\% Pd/KCC-1-PDETA, which confirmed the presence of Si, O, C, N, and Pd. XPS analysis also allowed determination of the electronic states of Pd on different silica supports (Fig. 4(b-f)). The deconvoluted Pd $3 d$ spectrum of 2 wt.\% Pd/KCC-1-PDETA (Fig. 4(b)) showed two doublet peaks: the strong peaks at 339.9 and
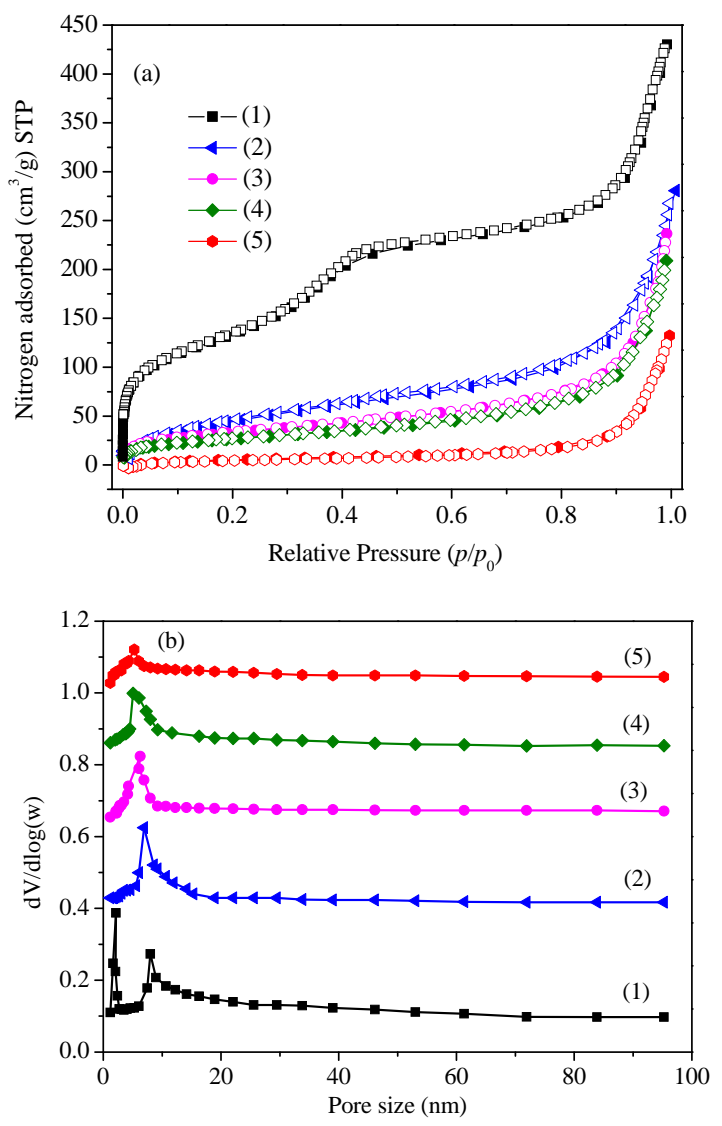

Fig. 3. (a) $\mathrm{N}_{2}$ adsorption-desorption isotherms at $77 \mathrm{~K}$ and (b) pore size distribution curves of (1) KCC-1, (2) KCC-1-PDETA, (3) 2 wt.\% Pd/KCC-1-PDETA, (4) 5 wt.\% Pd/KCC-1-PDETA, and (5) 10 wt.\% Pd/KCC-1-PDETA. 

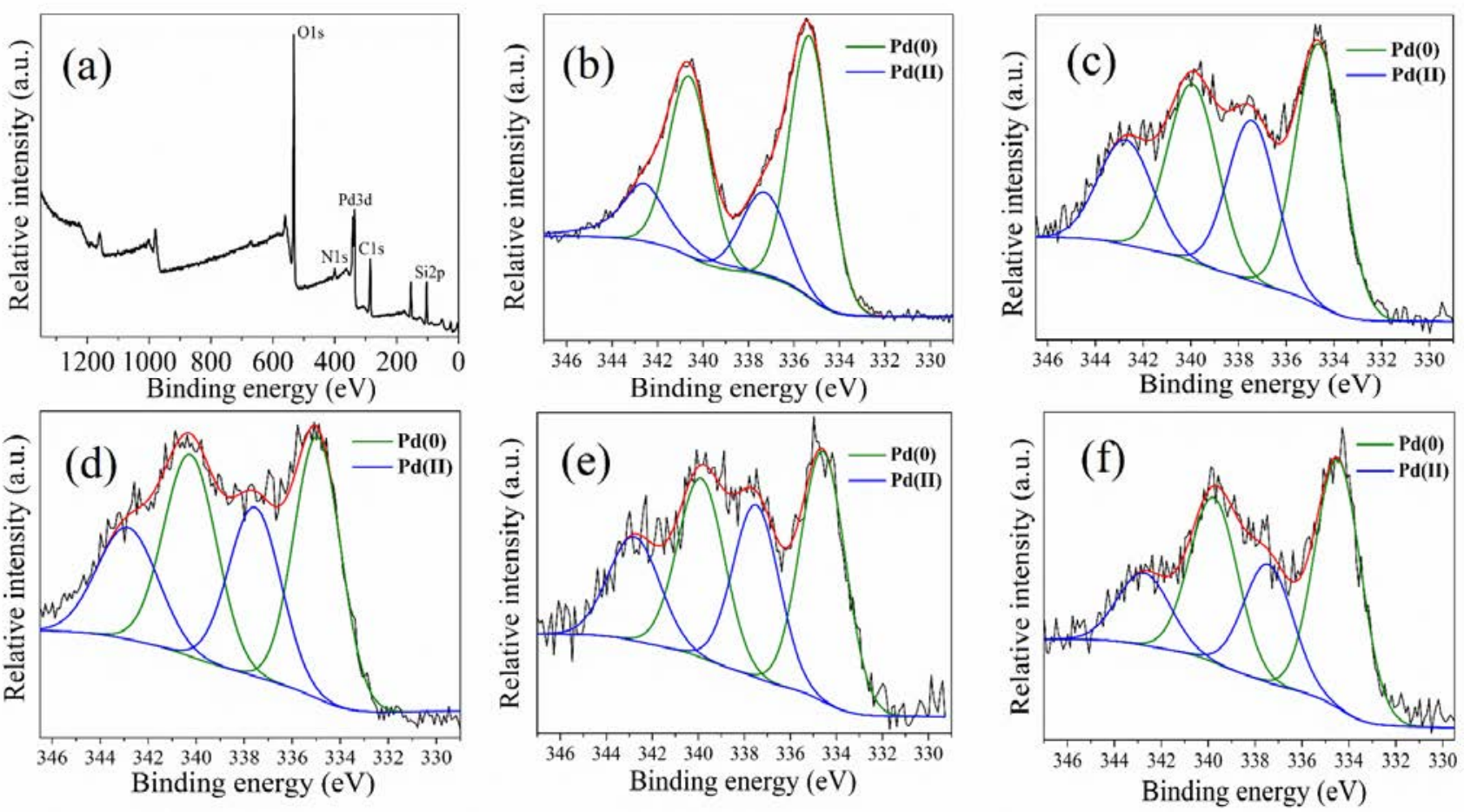

Fig. 4. (a) XPS survey spectrum of 2 wt.\% Pd/KCC-1-PDETA, and Pd 3d XP spectra of (b) 2 wt.\% Pd/KCC-1-PDETA, (c) 5 wt.\% Pd/KCC-1-PDETA, (d) 10 wt.\% Pd/KCC-1-PDETA, (e) 2 wt.\% Pd/MSF-PDETA, and (f) 2 wt.\% Pd/KIT-6-PDETA.

334.6 eV correspond to $\mathrm{Pd}(0) 3 d_{3 / 2}$ and $3 d_{5 / 2}$, respectively [29], and the low intensity peaks at 337.5 and $342.8 \mathrm{eV}$ were attributed to $\mathrm{Pd}(2+) 3 d_{3 / 2}$ and $3 d_{5 / 2}$, respectively [29]. These results indicate that $2 \mathrm{wt} . \% \mathrm{Pd} / \mathrm{KCC}-1$-PDETA still has almost $30 \%$ of $\mathrm{Pd}^{2+}$ ion (Table 1). The existence of $\mathrm{Pd}^{2+}$ species here indicates that some of the Pd precursor interacted strongly with the electron-enriched nitrogen on KCC-1 support due to the strong complexing ability of nitrogen species, and that it was difficult to reduce all the $\mathrm{Pd}^{2+}$ ions [30]. The positions of the $\mathrm{Pd} 3 d$ peaks and the amount of $\mathrm{Pd}^{2+}$ species for all other samples are shown in Fig. 4 and Table 1, respectively. The amounts of $\mathrm{Pd}^{2+}$ ions in the other as-prepared catalysts were higher than that in 2 wt.\% Pd/KCC-1-PDETA.

\subsection{Dehydrogenation of $\mathrm{HCOOH}$}

The catalytic performance of the Pd-supported silica catalysts towards FA decomposition in the absence of additives was examined, and the obtained results are given in Fig. 5. Fig. 5(a) shows the total volume of the generated gas $\left(\mathrm{CO}_{2}+\mathrm{H}_{2}\right)$ versus reaction time in the $\mathrm{FA}$ aqueous solution $\left(5 \mathrm{mmol} \mathrm{FA,} n_{\mathrm{Pd}} / n_{\mathrm{FA}}=\right.$ $0.01,15 \mathrm{~mL} \mathrm{H}_{2} \mathrm{O}$ ) in the presence of $2 \mathrm{wt} . \%$ Pd/KCC-1-PDETA, 2
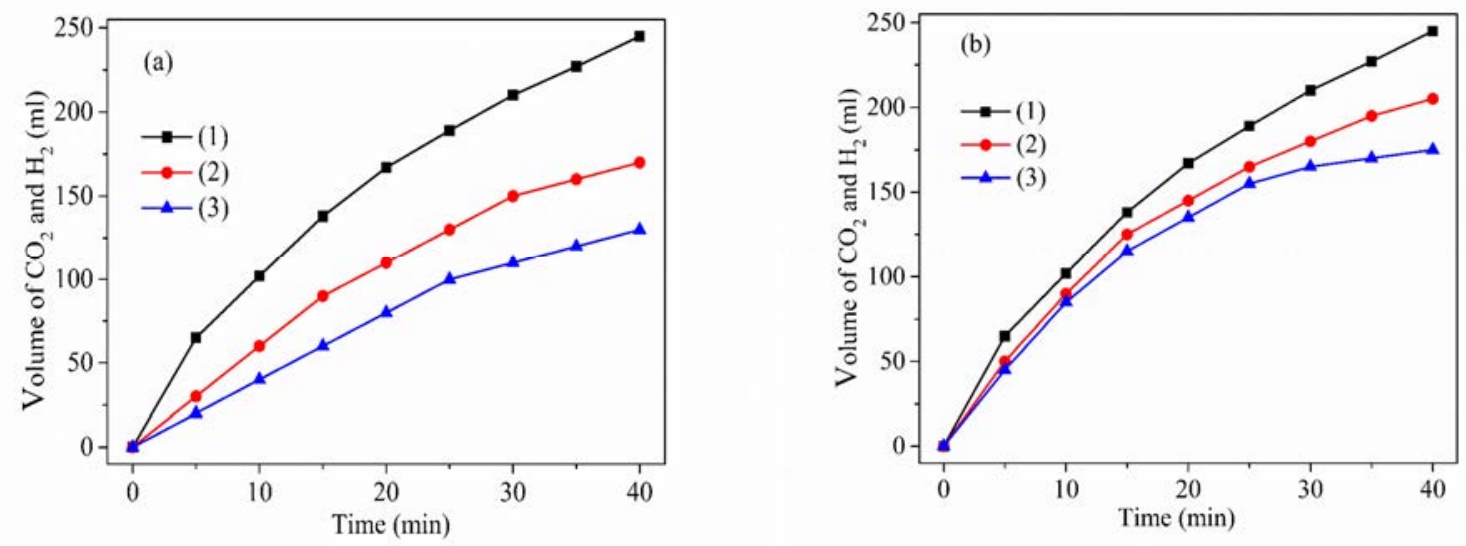

Fig. 5. Total gas volume $\left(\mathrm{CO}_{2}+\mathrm{H}_{2}\right)$ versus time ( $5 \mathrm{mmol} \mathrm{FA}, n_{\mathrm{Pd}} / n_{\mathrm{FA}}=0.01,15 \mathrm{~mL}$ water, $323 \mathrm{~K}$ ) catalyzed by (a) 2 wt. $\%$ Pd/KCC-1-PDETA (1), 2 wt.\% Pd/MSF-PDETA (2), and 2 wt.\% Pd/KIT-6-PDETA (3), and (b) 2 wt.\% Pd/KCC-1-PDETA (1), 5 wt.\% Pd/KCC-1-PDETA (2), and 10 wt.\% Pd/KCC-1-PDETA (3). 
Table 2

TOF values for FA decomposition over various heterogeneous catalysts without any additives.

\begin{tabular}{|c|c|c|c|}
\hline Catalyst & Temperature (K) & TOF $\left(h^{-1}\right)$ & Reference \\
\hline \multirow[t]{4}{*}{2 wt.\% Pd/KCC-1-PDETA } & 323 & $332^{a}$ & This work \\
\hline & 313 & 197 & This work \\
\hline & 303 & 151 & This work \\
\hline & 298 & $122^{\mathrm{a}}$ & This work \\
\hline 2 wt.\% Pd/MSF-PDETA & 323 & $147^{\mathrm{a}}$ & This work \\
\hline 2 wt.\% Pd/KIT-6-PDETA & 323 & $97^{\mathrm{a}}$ & This work \\
\hline 5 wt.\% Pd/KCC-1-PDETA & 323 & $242^{a}$ & This work \\
\hline 10 wt.\% Pd/KCC-1-PDETA & 323 & $222^{\mathrm{a}}$ & This work \\
\hline $\mathrm{Pd} \mathrm{MnOx} / \mathrm{NH}_{2}-\mathrm{SiO}_{2}$ & 323 & $1300^{\mathrm{a}}$ & {$[40]$} \\
\hline $\mathrm{PdAg} / \mathrm{NH}_{2}-\mathrm{UiO}-66$ & 323 & 525 & {$[31]$} \\
\hline $\mathrm{PdAg} / \mathrm{C}$ & 323 & 382 & [8] \\
\hline $\mathrm{Ag} @ \mathrm{Pd} / \mathrm{C}$ & 323 & 252 & {$[41]$} \\
\hline $\mathrm{PdAu} / \mathrm{C}$ & 323 & 230 & {$[42]$} \\
\hline Pd/zeolite & 323 & 59 & {$[13]$} \\
\hline Pd/MCTP-1 & 323 & 52 & [43] \\
\hline $\mathrm{PdAgMn} / \mathrm{NH}_{2}-\mathrm{SiO}_{2}$ & 313 & $1430^{\mathrm{a}}$ & {$[44]$} \\
\hline $\mathrm{PdAg} /$ resin & 337 & 820 & {$[45]$} \\
\hline $\mathrm{Pd} / \mathrm{NH}_{2}-\mathrm{KIE}-6$ & 298 & $1269^{a}$ & {$[46]$} \\
\hline $\mathrm{PdAg} / \mathrm{C}$ & 298 & 90 & {$[47]$} \\
\hline $\mathrm{PdMn} / \mathrm{NH}_{2}-\mathrm{KIE}-6$ & 298 & $98^{a}$ & {$[48]$} \\
\hline Au@Pd/N-rGO & 298 & 89 & [49] \\
\hline CoAuPd/DNA-rGO & 298 & 85 & {$[50]$} \\
\hline CoAuPd/C & 298 & $80^{a}$ & {$[10]$} \\
\hline $\mathrm{NiAuPd} / \mathrm{C}$ & 298 & 12 & {$[51]$} \\
\hline $\mathrm{AuPd}-\mathrm{CeO}_{2} / \mathrm{N}-\mathrm{rGO}$ & 298 & 53 & {$[52]$} \\
\hline Pd-poly(allyl-amine) & 296 & 46 & [53] \\
\hline
\end{tabular}

a TOF is calculated using the first $20 \%$ conversion of FA.

wt.\% Pd/MSF-PDETA, and 2 wt.\% Pd/KIT-6-PDETA at $323 \mathrm{~K}$. Clearly, 2 wt.\% Pd/KCC-1-PDETA was the most active catalyst among these three (Fig. 5(a-1)) and $245 \mathrm{~mL}$ of gas mixture $\left(\mathrm{CO}_{2}+\mathrm{H}_{2}\right)$ evolved within $40 \mathrm{~min}$, corresponding to complete dehydrogenation of FA as calculated by eqn. (S1). The TOF (eqn. (S2)) during the first $20 \%$ conversion of FA was calculated to be $332 \mathrm{~h}^{-1}$ without any additives at $323 \mathrm{~K}$, which is comparable to the best palladium-based heterogeneous catalysts reported for FA decomposition reaction (Table 2). By comparison, the gas production profiles of $2 \mathrm{wt} . \%$ Pd/MSF-PDETA and 2 wt.\% Pd/KIT-6-PDETA catalysts showed lower catalytic activities, although $\mathrm{H}_{2}$ was steadily released from the reaction mixture. The TOF of 2 wt.\% Pd/MSF-PDETA and 2 wt.\% Pd/KIT-6-PDETA up to 20\% conversion of FA were only 147 and $97 \mathrm{~h}^{-1}$, respectively, and the TOF of 2 wt.\% Pd/KCC-1-PDETA was almost 2 and 3 times higher than that of 2 wt.\% Pd/MSF-PDETA and 2 wt.\% Pd/KIT-6-PDETA, respectively. This difference is possibly due to the higher amount of the electron-rich nitrogen, smaller Pd particle size, and fibrous structure of KCC-1 that allowed more FA to access the catalytically active Pd sites [23,31-34]. The $n_{\mathrm{Pd}} / n_{\mathrm{FA}}$ was kept close to 0.01 in all three catalysts, and therefore the Pd loading difference is not a factor when comparing the catalytic activities.

Since some other researchers had used far higher Pd loadings than 2 wt.\% [12,31,35], Pd/KCC-1-PDETA with 5 wt.\% and 10 wt.\% Pd were also prepared to investigate how the Pd loading affects the catalytic activity of Pd/KCC-1-PDETA. FA decomposition tests were carried out using these catalysts at the same FA concentration and temperature as mentioned above, and the gas evolution profiles are presented in Fig. 5(b). For the $5 \mathrm{wt} . \%$ and $10 \mathrm{wt} . \%$ Pd loadings on KCC-1-PDETA, the volumes of released gas mixture were 205 and $175 \mathrm{~mL}$ with the TOF of 242 and $222 \mathrm{~h}^{-1}$, respectively (Fig. 5(b-2) and (b-3)). The decreased catalytic activity with increased Pd loading on KCC-1-PDETA seems to be a consequence of the bigger particle size and agglomeration of Pd nanoparticles [30] as shown in Fig. 2. Also, Fig. 4 and Table 1 show that at higher Pd loadings, the portion of the unreduced $\mathrm{Pd}^{2+}$ against $\mathrm{Pd}^{0}$ was higher, which contributes to a lower catalytic activity [36]. Therefore, 2 wt.\% Pd loaded on KCC-1-PDETA was used for further experiments in FA dehydrogenation reaction.

The influence of temperature on FA dehydrogenation over 2 wt.\% Pd/KCC-1-PDETA is shown in Fig. 6(a). An increase in the volume of liberated gas from 110 to $245 \mathrm{~mL}$ was observed when the temperature was increased from 298 to $323 \mathrm{~K}$, illustrating that a higher reaction temperature promotes FA dehydrogenation. However, since the FA boiling point is $373 \mathrm{~K}$, the
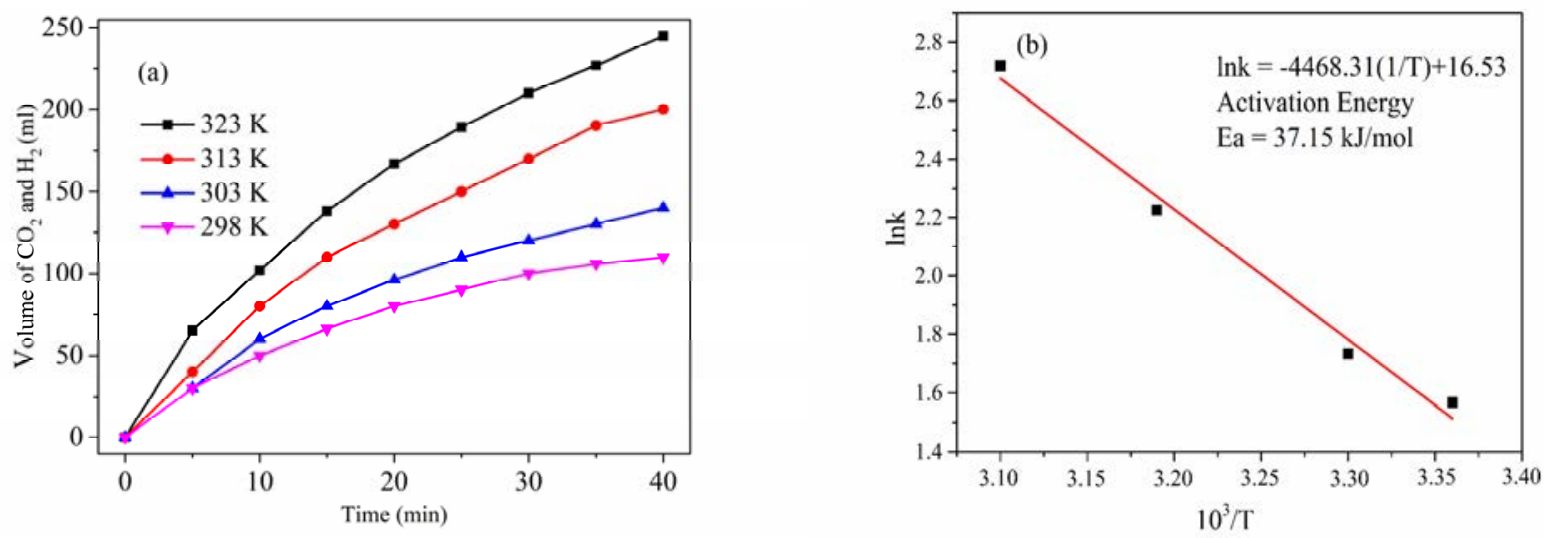

Fig. 6. (a) Total gas volume $\left(\mathrm{CO}_{2}+\mathrm{H}_{2}\right)$ versus time from the reactant solution $\left(5 \mathrm{mmol} \mathrm{FA}, n_{\mathrm{Pd}} / n_{\mathrm{FA}}=0.01,15 \mathrm{~mL}\right.$ water $)$ catalyzed by $2 \mathrm{wt} . \%$ Pd/KCC-1-PDETA at different temperatures and (b) the corresponding Arrhenius plot. 
FA will evaporate at above $323 \mathrm{~K}$, which limits the practical application of hydrogen generation [37]. The rate constant $k$ at different temperatures was determined from the slope of the linear portion of each plot in Fig. 6(a). The Arrhenius plot of $\ln k$ vs. $1 / T$ for 2 wt.\% Pd/KCC-1-PDETA is shown in Fig. 6(b). The obtained activation energy $\left(E_{\mathrm{a}}\right)$ is $37.15 \mathrm{~kJ} / \mathrm{mol}$, which is comparable to those of other previously reported catalysts $[5,35,38]$.

To confirm the absence of poisonous CO produced during the reaction, the evolved gas was treated with a trap (5 mol/L $\mathrm{NaOH}$ solution) at $323 \mathrm{~K}$ to remove $\mathrm{CO}_{2}$ (Fig. 7). The gas volume decreased to half after the $\mathrm{NaOH}$ treatment, indicating that practically $\mathrm{CO}$-free hydrogen was evolved from FA dehydrogenation over the $2 \mathrm{wt} \% \mathrm{Pd} / \mathrm{KCC}-1$-PDETA catalyst. GC analysis detected only the signals of $\mathrm{H}_{2}$ and $\mathrm{CO}_{2}$ without $\mathrm{CO}$ (detection limit: 10 ppm CO), which also confirmed the $\mathrm{H}_{2}$ selectivity of the catalyst for formic acid dehydrogenation.

Finally, the catalyst cycling experiment was conducted with 2 wt.\% Pd/KCC-1-PDETA catalyst in the additive-free dehydrogenation of FA at $323 \mathrm{~K}$ (Fig. 8). At the end of each reaction cycle, the Pd catalyst was recovered by filtration, washed with water several times, and dried at $60{ }^{\circ} \mathrm{C}(333 \mathrm{~K})$ for $12 \mathrm{~h}$ before reuse. After the fifth run, the recovered catalyst showed about $7 \%$ decline in catalytic activity (Fig. 8), which can be ascribed to a reduced number of active sites due to the Pd particles grown in size from $2.8 \mathrm{~nm}$ (fresh) to $3.3 \mathrm{~nm}$ (reused) (Fig. S5) [39]. ICP-OES analysis after the first run showed no Pd leaching (detection limit: $\sim 0.01 \mathrm{ppm}$ for $\mathrm{Pd}$ ) into the solution.

\section{Conclusions}

In summary, finely dispersed 2 wt.\% Pd nanoparticles deposited on KCC-1 were successfully prepared with a mean particle size of $2.8 \mathrm{~nm}$. The prepared sample was used as an efficient, robust, and selective catalyst for FA decomposition without additives at $323 \mathrm{~K}$. The catalytic performance of Pd nanoparticles deposited on KCC-1 was systematically evaluated and compared with that of the Pd nanoparticles deposited on conventional mesoporous silica materials (MSF and KIT-6)

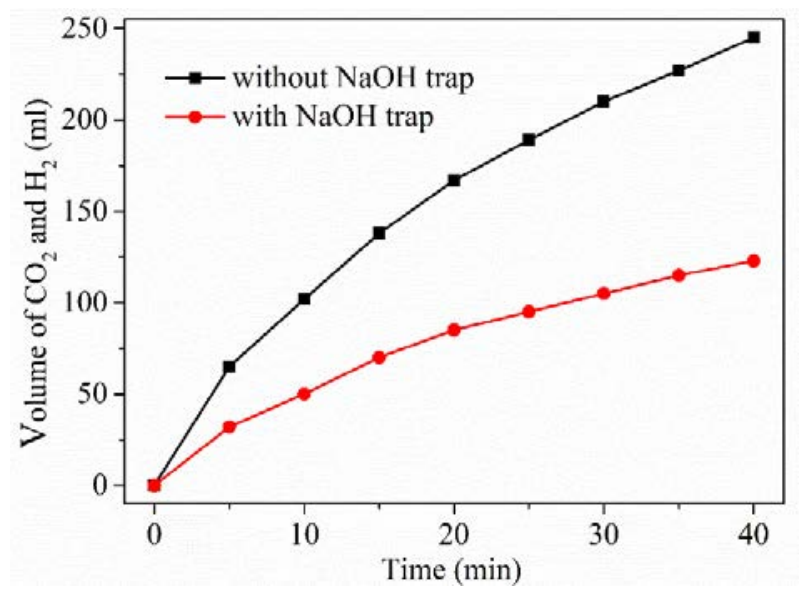

Fig. 7. Total gas volume $\left(\mathrm{CO}_{2}+\mathrm{H}_{2}\right)$ versus time $\left(5 \mathrm{mmol} \mathrm{FA}, n_{\mathrm{Pd}} / n_{\mathrm{FA}}=\right.$ $0.01,15 \mathrm{~mL}$ water, $323 \mathrm{~K}$ ) catalyzed by $2 \mathrm{wt} . \% \mathrm{Pd} / \mathrm{KCC}-1$-PDETA with and without a $\mathrm{NaOH}$ trap.

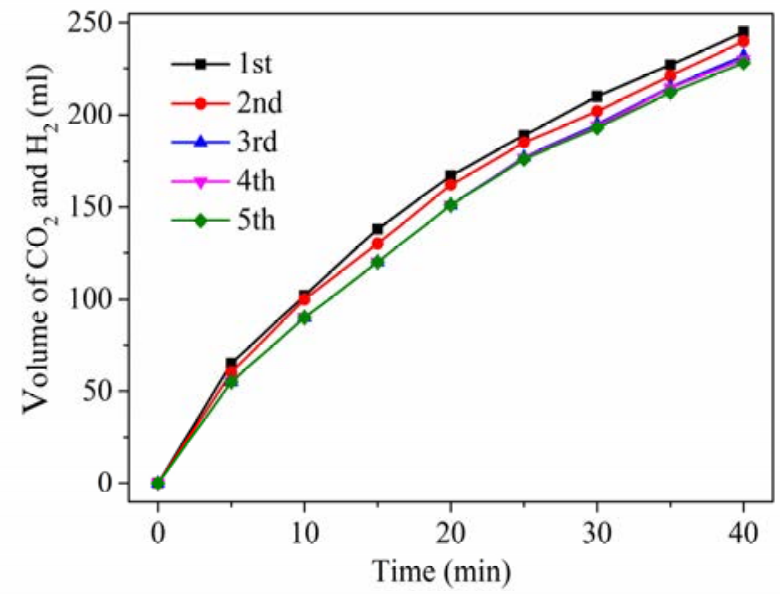

Fig. 8. Recycle test of 2 wt.\% Pd/KCC-1-PDETA in FA dehydrogenation $\left(5 \mathrm{mmol} \mathrm{FA}, n_{\mathrm{Pd}} / n_{\mathrm{FA}}=0.01,15 \mathrm{~mL}\right.$ water, $\left.323 \mathrm{~K}\right)$.

under the same conditions. The Pd/KCC-1-PDETA exhibited the best catalytic activity, with a TOF value of $332 \mathrm{~h}^{-1}$ and $100 \%$ of $\mathrm{H}_{2}$ selectivity for FA dehydrogenation. This can be attributed to the unique fibrous morphology of KCC-1, which helps to increase the FA accessibility to the catalytically active palladium nanoparticle sites in smaller size. The influence of Pd loading in the FA dehydrogenation was also investigated, showing that a sufficiently low loading of Pd resulted in smaller deposited Pd nanoparticles on KCC-1-PDETA, which led to the production of more $\mathrm{H}_{2}$ gas. Additionally, 2 wt.\% Pd/KCC-1-PDETA could maintain its catalytic activity after several recycles.

\section{References}

[1] K. Fujita, R. Kawahara, T. Aikawa, R. Yamaguchi, Angew. Chem. Int Ed., 2015, 54, 9057-9060.

[2] T. Umegaki, A. Seki, Q. Xu, Y. Kojima, J. Alloys Compd., 2014, 588, 615-621.

[3] M. Grasemann, G. Laurenczy, Energy Environ. Sci., 2012, 5, 8171-8181.

[4] S. Fukuzumi, T. Kobayashi, T. Suenobu, J. Am. Chem. Soc., 2010, 132, 1496-1497.

[5] Y. Chen, Q. L. Zhu, N. Tsumori, Q. Xu, J. Am. Chem. Soc., 2015, 137, 106-109.

[6] F. Z. Song, Q. L. Zhu, N. Tsumori, Q. Xu, ACS Catal., 2015, 5, 5141-5144.

[7] M. Ojeda, E. Iglesia, Angew. Chem. Int. Ed., 2009, 48, 4800-4803.

[8] S. Zhang, Ö. Metin, D. Su, S. Sun, Angew. Chem. Int. Ed., 2013, 52, 3681-3684.

[9] Y. L. Qin, J. Wang, F. Z. Meng, L. M. Wang, X. B. Zhang, Chem. Commun., 2013, 49,10028-10030.

[10] Z. L. Wang, J. M. Yan, Y. Ping, H. L. Wang, W. T. Zheng, Q. Jiang, Angew. Chem. Int. Ed., 2013, 52, 4406-4409.

[11] M. H. Jin, D. Oh, J. H. Park, C. B. Lee, S. W. Lee, J. S. Park, K. Y. Lee, D. W. Lee, Sci. Rep., 2016, 6, 33502/1-33502/12.

[12] D. W. Lee, M. H. Jin, J. C. Park, C. B. Lee, D. Oh, S. W. Lee, J. W. Park, J. S. Park, Sci. Rep., 2015, 5, 15931/1-15931/11.

[13] M. Navlani-García, M. Martis, D. Lozano-Castelló, D. Cazorla-Amorós, K. Moribc, H. Yamashita, Catal. Sci. Technol., 2015, 5, 364-371. 


\section{Graphical Abstract}

Chin. J. Catal., 2019, 40: 1704-1712 doi: S1872-2067(19)63303-6

Catalytic dehydrogenation of formic acid over palladium nanoparticles immobilized on fibrous mesoporous silica KCC-1

Siqian Zhang, Yingjie Qian, Wha-Seung Ahn*

Inha University, Republic of Korea

Highly efficient dehydrogenation of formic acid without any additives at 323 $\mathrm{K}$ was achieved using Pd nanoparticles supported on amine-functionalized fibrous silica KCC-1.

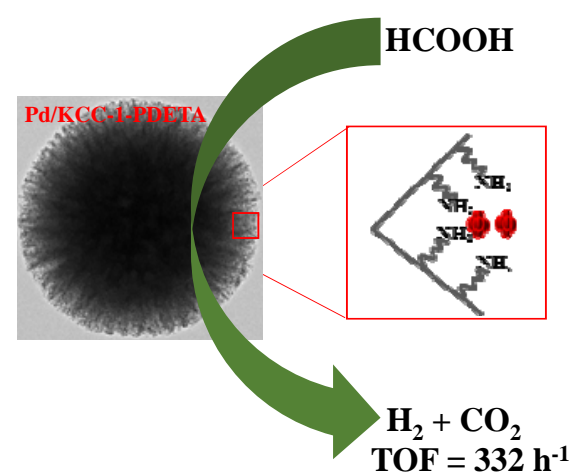

- Pd (nanoparticle size $=2.75 \mathrm{~nm}$ )

${ }_{\mathrm{B}_{\mathrm{B}}} \mathrm{N}$-(3-trimethoxysilylpropyl) diethylenetriamine (PDETA)
[14] Z. S. Qureshi, P. B. Sarawade, M. Albert, V. D’Elia, M. N. Hedhili, K. Kçhler, J. M. Basset, ChemCatChem, 2015, 7, 635-642.

[15] N. Bayal, B. Singh, R. Singh, V. Polshettiwar, Sci. Rep., 2016, 6, 24888-24899.

[16] E. Febriyanti, V. Suendo, R. R. Mukti, A. Prasetyo, A. F. Arifin, M. A. Akbar, S. Triwahyono, I. N. Marsih, Ismunandar, Langmuir, 2016, 32, 5802-5811.

[17] A. Fihri, M. Bouhrara, U. Patil, D. Cha, Y. Saih, V. Polshettiwar, ACS Catal., 2012, 2, 1425-1431.

[18] X. Le, Z. Dong, Y. Liu, Z. Jin, T. Huy, M. Le, J. Ma, J. Mater. Chem. A, 2014, 2, 19696-19706.

[19] A. N. Chermahini, F. Shahangi, H. A. Dabbagh, M. Saraji, RSC Adv., 2016, 6, 33804-33810.

[20] K. Yu, X. Zhang, H. Tong, X. Yan, S. Liu, Mater. Lett., 2013, 106, 151-154.

[21] U. Patil, A. Fihri, A. Emwas, V. Polshettiwar, Chem. Sci., 2012, 3, 2224-2229.

[22] S. H. Joo, J. Y. Park, C. K. Tsung, Y. Yamada, P. Yang, G. A. Somorjai, Nat. Mater., 2009, 8, 126-131.

[23] C. K. P. Neeli, Y. M. Chung, W. S. Ahn, ChemCatChem, 2017, 9 , 4570-4579.

[24] B. Singh, V. Polshettiwar, J. Mater. Chem. A, 2016, 4, 7005-7019.

[25] M. Dhiman, B. Chalke, V. Polshettiwar, ACS Sustainable Chem. Eng., 2015, 3, 3224-3230.

[26] M. Bouhrara, C. Ranga, A. Fihri, R. R. Shaikh, P. Sarawade, A. H. Emwas, M. N. Hedhili, V. Polshettiwar, ACS Sustainable Chem. Eng., 2013, 1, 1192-1199.

[27] M. Martis, K. Mori, K. Fujiwara, W. S. Ahn, H. Yamashita, J. Phys. Chem. C, 2013, 117, 22805-22810.

[28] X. Chen, G. Wu, J. Chen, X. Chen, Z. Xie, X. Wang, J. Am. Chem. Soc., 2011, 133, 3693-3695.

[29] S. Akbayrak, Y. Tonbul, S. Özkar, Appl. Catal. B, 2017, 206, 384-392.

[30] M. Zacharska, L. G. Bulusheva, A. S. Lisitsyn, S. Beloshapkin, Y. Guo, A. L. Chuvilin, E. V. Shlyakhova, O. Y. Podyacheva, J. J. Leahy, A. V. Okotrub, D. A. Bulushev, ChemSusChem, 2017, 10, 720-730.

[31] S. T. Gao, W. Liu, C. Feng, N. Z. Shang, C. Wang, Catal. Sci. Technol., 2016, 6, 869-874.

[32] Q. Liu, X. Yang, Y. Huang, S. Xu, X. Su, X. Pan, J. Xu, A. Wang, C. Liang,
X. Wang, T. Zhang, Energy Environ. Sci., 2015, 8, 3204-3207.

[33] D. W. Lee, M. H. Jin, J. H. Park, Y. J. Lee, Y. C. Choi, J. C. Park, D. H. Chun, ACS Sustainable Chem. Eng., 2018, 6, 12241-12250.

[34] C. Cui, Y. Tang, M. A. Ziaee, D. Tian, R. Wang, ChemCatChem, 2018, 10, 1431-1437.

[35] J. Li, W. Chen, H. Zhao, X. Zheng, L. Wu, H. Pan, J. Zhu, Y. Chen, J. Lu, J. Catal., 2017, 352, 371-381.

[36] Z. L. Wang, J. M. Yan, H. L. Wang, Y. Ping, Q. Jiang, J. Mater. Chem. A, 2013, 1, 12721-12725.

[37] J. P. Zhou, J. Zhang, X. H. Dai, X. Wang, S. Y. Zhang, Int. J. Hydrogen Energy, 2016, 41, 22059-22066.

[38] Q. L. Zhu, N. Tsumori, Q. Xu, Chem. Sci, 2014, 5, 195-199.

[39] H. M. Dai, B. Q. Xia, L. Wen, C. Du, J. Su, W. Luo, G. Z. Cheng, Appl. Catal. B, 2015, 165, 57-62.

[40] A. Bulut, M. Yurderi, Y. Karatas, M. Zahmakiran, H. Kivrak, M. Gulcan, M. Kaya, Appl. Catal. B, 2015, 164, 324-333.

[41] K. Tedsree, T. Li, S. Jones, C. W. A. Chan, K. M. K. Yu, P. A. J. Bagot, E. A. Marquis, G. D. W. Smith, S. C. E. Tsang, Nat. Nanotechnol., 2011, 6, 302-307.

[42] Ö. Metin, X. Sun, S. Sun, Nanoscale, 2013, 5, 910-912.

[43] S. Zhang, Y. R. Lee, H. J. Jeon, W. S. Ahn, Y. M. Chung, Mater. Lett., 2018, 215, 211-213.

[44] A. Bulut, M. Yurderi, Y. Karatas, Z. Say, H. Kivrak, M. Kaya, M. Gulcan, E. Ozensoy, M. Zahmakiran, ACS Catal., 2015, 5, 6099-6110.

[45] K. Mori, M. Dojo, H. Yamashita, ACS Catal., 2013, 3, 1114-1119.

[46] M. H. Jin, J. H. Park, D. Oh, S. W. Lee, J. S. Park, K. Y. Lee, D. W. Lee, Int. J. Hydrogen Energy, 2018, 43, 1451-1458.

[47] Y. Huang, J. Xu, T. Long, Q. Shuai, Q. Li, J. Nanosci. Nanotechnol., 2017, 17, 3798-3802.

[48] D. W. Lee, M. H. Jin, Y. J. Lee, J. H. Park, C. B. Lee, J. S. Park, Sci. Rep., 2016, 6, 26474/1-26474/9.

[49] Z. L. Wang, J. M. Yan, H. L. Wang, Y. Ping, Q. Jiang, J. Mater. Chem. A, 2013, 1, 12721-12725.

[50] Z. L. Wang, H. L. Wang, J. M. Yan, Y. Ping, S. I. O, S. J. Li, Q. Jiang, Chem. Commun., 2014, 50, 2732-2734.

[51] Z. L. Wang, Y. Ping, J. M. Yan, H. L. Wang, Q. Jiang, Int. J. Hydrogen Energy, 2014, 39, 4850-4856.

[52] Z. L. Wang, J. M. Yan, Y. F. Zhang, Y. Ping, H. L. Wang, Q. Jiang, Nanoscale, 2014, 6, 3073-3077. 


\title{
纤维状中孔硅胶KCC-1负载的钯纳米颗粒上甲酸催化脱氢反应
}

\author{
Siqian Zhang, Yingjie Qian, Wha-Seung Ahn ${ }^{*}$ \\ 仁荷大学化学与化学工程系, 仁川402-751, 韩国
}

\begin{abstract}
摘要: 在 $N$-(3-三甲氧基硅丙基)二乙烯三胺(PDETA)功能化的纤维状硅胶KCC-1上负载了均一的、平均粒径为 $2.8 \mathrm{~nm}$ 的Pd 纳米粒子 (Pd/KCC-1-PDETA), 采用粉末 X射线衍射、 $X$ 射线光电子能谱和 $\mathrm{N}_{2}$ 吸附-脱附等温线对其进行了表征, 并将其作为 催化剂用于无添加剂的甲酸脱氢制 $\mathrm{H}_{2}$ 的反应中. 同时还制备了另外两个中孔硅胶材料(MSF和KIT-6)负载的Pd纳米粒子, 以考察反应中催化剂的载体效应. 结果表明, Pd/KCC-1-PDETA催化剂表现出很高的催化性能(323 K时TOF值为 $332 \mathrm{~h}^{-1}$, 氢 气选择性 $100 \%$ ). 这归结为KCC-1独特的纤维状形貌和胺基基团的存在, 从而降低了Pd颗粒尺寸, 促进了反应物与催化活 性位 Pd 的接触. 还考察了 Pd负载量 (2-10 wt \%)、反应温度和反应时间对脱氢反应性能的影响. 反应结束后, Pd/KCC-1-PDETA催化剂容易回收, 可重复使用5次而催化性能未见明显下降, 表现出较好的重复使用性能.
\end{abstract}

关键词: 纤维状纳米硅胶; KCC-1; 钯纳米颗粒; 储氢; 甲酸脱氢

收稿日期: 2018-12-09. 接受日期: 2019-01-14. 出版日期: 2019-11-05.

*通讯联系人. 电话: +82-328-607466; 传真:+82-328-720959; 电子信箱: whasahn@inha.ac.kr

本文的电子版全文由Elsevier出版社在ScienceDirect上出版(http://www.sciencedirect.com/science/journal/18722067). 